\title{
Modernization of a Chemical Nickeling Unit for Metal Products
}

\author{
Andrey Borisenko ${ }^{1, ~}{ }^{*}$, Vadim Khramtsov ${ }^{1}$, Vladimir Nemtinov $^{1}$, and Yulia Nemtinova ${ }^{1,2}$ \\ ${ }^{1}$ Tambov State Technical University, 392000, Sovetskaya st., 106, Tambov, Russia \\ ${ }^{2}$ Tambov State Tambov State University named after G.R. Derzhavin, 392000, Internatsionalnaya st., \\ 33, Tambov, Russia
}

\begin{abstract}
Metal protective coatings have a number of advantages, including high corrosion resistance, resistance to mechanical stress, and attractive appearance. The article analyzes the requirements for technological equipment for chemical nickel plating of items made of carbon steels, aluminum, titanium, copper and their alloys. The disadvantages of standard equipment (chemical nickel-plating units functioning as separate technological units) during its operation as a part of a plating line are formulated. The results of modernization and design development for an improved unit for chemical nickel plating of metal products with repeated use of the plating solution are presented. The calculation of the walls' strength, thermal calculation of tubular electric heaters, the calculation of a single-side suction without blowing with a suction gap in the horizontal plane were performed. Pneumatic cylinders with the required working force and stroke were selected. The modernized unit is more compact, easier to maintain, and its design allows it to function as a part of a plating line. Testing of the unit in a plating section of a real manufacturing facility showed its high efficiency.
\end{abstract}

\section{Introduction}

Every year, because of corrosion (destruction due to electrochemical or chemical effects of the environment), engineering structures, ships, machines, apparatuses and other devices prematurely fail, and various accidents may occur [1]. To reduce metal losses and protect products from corrosion, along with the use of chemically resistant materials, various types of protective coatings are widely used for isolating metal product from the environment and thereby preventing its contact with air oxygen, water, etc.

It is possible to identify metal protective coating (copper, tin, zinc, chromium etc.), chemical (strong film of oxides, phosphates, etc.) and non-metal - (varnishes, paints, resin, enamel, etc.).

Metal protective coatings have several advantages, including high corrosion resistance, resistance to mechanical influences, attractive appearance.

An increase in the hardness of the rubbing surfaces due to application of electroplating coatings allows to increase the operational life of the rubbing surfaces, for example, the

\footnotetext{
* Corresponding author: borisenko@mail.gaps.tstu.ru
} 
cylinders of internal combustion engines [2], [3] Chrome coating proved to be one of the hardest. However, due to its high price, nickel coating with similar hardness is often used instead. In addition to high hardness, which exceeds the hardness of protective coating of cadmium, zinc and tin, nickel coating is one of the most resistant to corrosion.

The equipment necessary for nickel plating is designed based on specific production tasks solved by a particular enterprise [4], [5]. If the equipment is installed in specialized electroplating shops [6], this makes it possible to use existing baths and devices for cleaning parts, degreasing, washing, drying, etc. [7].

At the same time, it is necessary to take into account the specifics of a particular production including the size and layout of the shop or site, design and location of electroplating baths, presence or absence of the required auxiliary equipment (pumps, heat exchangers, filter units, etc.), location of water supply, power supply and ventilation systems [8]-[11].

There are two possible ways of applying nickel coatings: electrolytic and chemical [12]. This article focuses on modernization of the unit for chemical nickel plating for products made of carbon steels, aluminum, titanium, copper and their alloys with repeated use of the plating solution [13], [14].

\section{Requirements for technological equipment}

An important step in the process of developing a chemical nickel plating line is selection of technological equipment that has the following requirements [15]-[18].

During the nickel plating process, no nickel deposits should occur on the walls of the bath. It is necessary to provide for the possibility of mechanical or chemical cleaning of the bath from the powdered nickel falling out in the form of a solid precipitate. During the process, it is important to observe all its technological parameters. The quality of the coating is affected, in particular, by composition, concentration and operating temperature of the electrolyte.

One of the ways to prevent deposition of nickel on the bath walls is to provide a positive potential (the so-called anode protection).

Changing the composition of an electrolyte (its impurity) leads to defects. To purify an electrolyte, it is necessary to provide a filtration system. Maintenance of its chemical composition is provided by the corrective solution supply system.

To achieve uniform electrolyte concentration, temperature and stabilization of other technological parameters throughout the entire volume of a plating bath, a solution mixing system is necessary, for example, the one using a bubbling or a swing / shake mechanism of the suspension with parts.

It is possible to maintain the required working temperature of the solution in the bath using both external and internal heating systems. For external heating, a mantle, in which a liquid coolant or heating steam is supplied, can be used. For internal heating, it is possible to use electric heaters (heating elements) or coils directly immersed in the solution.

To monitor the temperature, as well as the level of the solution, a bath should be equipped with appropriate sensors.

The CNPU series (Chemical Nickel-Plating Unit) was chosen as the base unit. These units are used for chemical nickel plating of parts with complex configuration made of carbon and corrosion-resistant steels, aluminum, titanium, copper and their alloys. A special feature of their design is that technological operations (heating of the solution, coating, adjustment of the plating solution, removal of mechanical impurities) are carried out in one tank. This allows to reduce energy consumption and production area by $25 \%$ in comparison with other units. Adjustment of the working solution (maintenance of concentration of 
nickel sulfuric acid, sodium hypophosphite and required $\mathrm{pH}$ value) is carried out during the nickel plating process by adding a concentrate according to the specified program.

It is intended to use this unit as a part of a plating line [19]. However, the design and characteristics of a standard chemical nickel plating plant did not meet the necessary requirements due to the following reasons:

1) Configuration and location of pipe fittings, controls and other key elements of the unit did not fit well into the designed plating line;

2) To prevent the process of chemical nickel plating on solid particles of dirt deposited on the bottom, the standard unit provides for cooling the bottom of the bath with running water (the operating temperature of the solution should be in the narrow range of $90-92^{\circ} \mathrm{C}$ and when the temperature decreases, the reaction does not occur). Additionally, the unit must be equipped with a solution filtration unit;

3) Stationary tanks with corrective solutions and metering pumps in a standard unit are located side by side on a separate stand, which is not acceptable for a unit operating as part of a plating line;

4) The rods for hanging the coated parts on the original unit were located across the bath, while the operation of the unit as part of the plating line requires a longitudinal arrangement.

\section{Modernization of a chemical nickel plating unit}

To improve structural and operational characteristics of a standard chemical nickel-plating unit, the following modernization was carried out:

A solution filtration system was added with its subsequent return to the reactor bath through the nozzles. At the same time, the cooling system of the bottom of the reactor is left unchanged and during operation it is possible to use either filtration of the solution or cooling to the discretion of the operator:

1) One tank with a corrective solution (a solution of ammonia water to increase the $\mathrm{pH}$ level of the solution) and a metering pump were integrated into the design of the bath (they were located directly on the frame of the unit and hidden behind the panels of the coating), so the unit became more compact;

2) In addition to an integrated stationary tank, mobile containers have been added to adjust the solution. As part of the designed electroplating line, it is planned to use three chemical nickel-plating units. At the same time, mobile tanks can serve all three units and stationary tanks standing separately on the stand are not required;

3) The original suspension shaking system on four pneumatic cylinders was converted to two pneumatic cylinders, which simplified the design of the suspension frame, reduced both the cost of pneumatic equipment and simplified its adjustment. Pneumatic cylinders with the required force and the required stroke were selected [20];

4) The suspension rod of the parts is converted to a longitudinal arrangement, while the set for the transverse arrangement of the rod is preserved and, if necessary, the rod can be used in a transverse arrangement;

5) All pipelines and pneumatic lines are laid anew and completely hidden in the body of the unit, while making special windows for quick access to pneumatic cylinders and pipelines.

\section{Development of the unit's body}

The central supporting structure of the plating unit is its body, which is operated in aggressive conditions of the main working mean. Due to their characteristics (high thermal stability, good weldability, high corrosion resistance), titanium alloys are used as a material 
for welded structures for various purposes [21], [22]. Studies of titanium alloys as a structural metal have shown its high corrosion resistance in various aggressive environments, including in all electrolytes of an alkaline, slightly acidic and acidic nature [23].

Technical titanium VT1-00 GOST 19807-91 (titanium alloy VT1-00) was chosen as the material for the plating bath. Calculations of the strength of the unit's walls were conducted.

Source data.

Internal dimensions of the unit (length $\times$ width $\times$ height) $-900 \times 500 \times 650 \mathrm{~mm}$.

Material - titanium VT1-00. Medium - nickel sulfuric acid with the concentration of 20 ... $25 \mathrm{~g} / \mathrm{l}$, sodium phosphoric acid $20 \ldots 25 \mathrm{~g} / \mathrm{l}$, aminoacetic acid with the concentration of $15 \ldots 25 \mathrm{~g} / \mathrm{l}$, sodium acetic acid with the concentration of $15 \ldots 25 \mathrm{~g} / \mathrm{l}$, thiourea $0.001 \mathrm{mg}$, solution density $p=1,210103 \mathrm{~kg} / \mathrm{m}^{3}$. The height of the liquid column $H_{\mathrm{j}}=0.65 \mathrm{~m} ; \beta_{\mathrm{n} . \mathrm{d}}$. nominal permissible voltage, $\beta_{\text {n.d. }}=\sigma_{t} / n_{T}$ Yield area for titanium VT1-00 (body) $\sigma_{t}=350$ $\mathrm{MN} / \mathrm{m}^{2}$, safety margin $n_{T}=1,65 ; \beta_{\mathrm{n} . \mathrm{d}}=350: 1,65=212 \mathrm{MN} / \mathrm{m}^{2}$.

Calculation of the walls thickness of the unit's body.

$P$ - hydrostatic pressure, $P=P_{\mathrm{c}}+g \rho H_{\mathrm{g}} \times 10^{-6} \mathrm{MN} / \mathrm{m}^{2}$, where the excessive pressure $P_{\mathrm{c}}=0 ; g=9,81 \mathrm{~m} / \mathrm{s}^{2} ;$ height of the liquid column $H_{\mathrm{g}}=0,65 \mathrm{~m}$.

$P=9,81 \cdot 1,2 \cdot 103 \cdot 0,55 \cdot 10^{-6}=0,0076 \mathrm{MN} / \mathrm{m}^{2}$.

A vertical position of the horizontal edge is determined by the formulas:

$H=0,18 \cdot H_{\mathrm{g}}=0,099 \mathrm{~m}$, we accept $0,1 \mathrm{~m}$;

The calculation of the pressure on the wall of the unit is carried out according to the formula:

$P=P_{\mathrm{g}}=P_{\mathrm{c}}+g \rho H_{\mathrm{g}} \cdot 10^{-6}=0,0076 \mathrm{MN} / \mathrm{m}^{2}$.

The wall thickness without reinforcement is determined by the formula:

$S=K H \sqrt{ }\left(H / \beta_{n, d}\right)=0,0018 \mathrm{~m}$,

where $K$-coefficient depending on the method of fixing the wall.

Taking into account the rounding, we take wall thickness $S=2 \mathrm{~mm}$.

Thermal calculation of tubular electric heaters (TEH) is made to determines the electric power and the heat exchange surface required both for heating the electrolyte in the bath and for maintaining its temperature during operation. The installed capacity of electric heaters was $20 \mathrm{~kW}$, the cooling surface of the bottom $0,45 \mathrm{~m}^{2}$.

To ensure the removal of harmful substances released from the surface of the solutions, the unit is equipped with a single-board suction. The calculation of the onboard suction was carried out and consisted from determining geometric dimensions (height and width of the slot, as well as the diameter of the nozzle) and the flow rate of the removed air. The flow rate of the removed air was $1665,46 \mathrm{~m}^{3} / \mathrm{h}$. The calculations were carried out using the "Electroplating Calculation Program" developed by the authors.

As a result, the unit for the chemical nickel plating process has been modernized up to the following characteristics:

Volume of the plating solution, $\mathrm{dm}^{3}$, not more than Internal dimensions of the bath, $\mathrm{mm}$, not more than

$270 \pm 5$

Overall dimensions of the installation, $\mathrm{mm}$, not more than

Weight of the unit (without solution), kg, not more than

$900 \times 500 \times 650$

$1280 \times 1270 \times 1330$

Power consumption, $\mathrm{kW}$, not more than

The amplitude of the shaking mechanism, mm, not more than

Frequency of the shaking mechanism, Hz, not more than

Voltage of the anode protection power supply, V, not more than

Heating time of the solution, min, not more than

Working temperature of the solution in the working area, ${ }^{\circ} \mathrm{C}$, not more than $90 \pm 2$

Surface of simultaneously loaded parts, $\mathrm{m}^{2}$, max. 
Bottom cooling surface, $\mathrm{m}^{2}$

0,45

Amount of filtrate, $\mathrm{m}^{3} / \mathrm{h}$

$0,6-1,2$

Degree of purification, microns

10

The design documentation is developed using the SolidWorks software package. A general three-dimensional model is shown in Figure 1. Figure 2 shows the nodes of the unit.

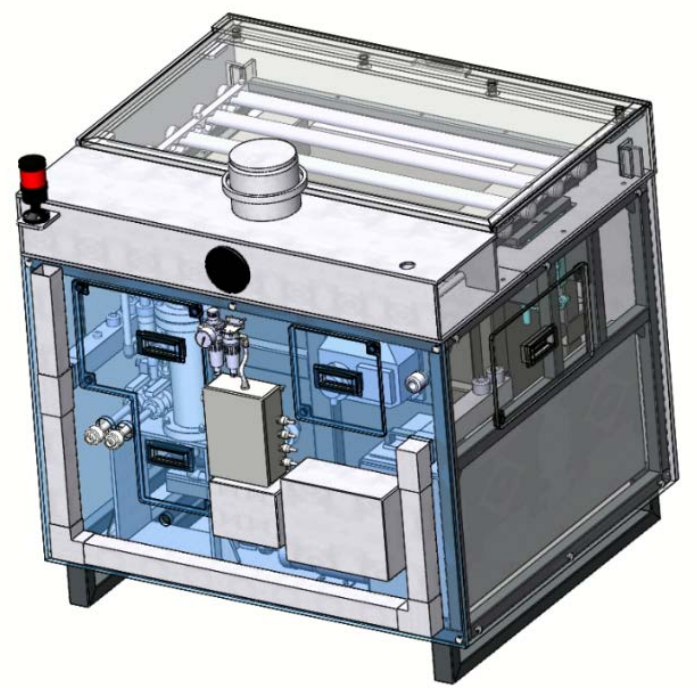

Fig. 1. General 3D-view of a chemical nickel plating unit

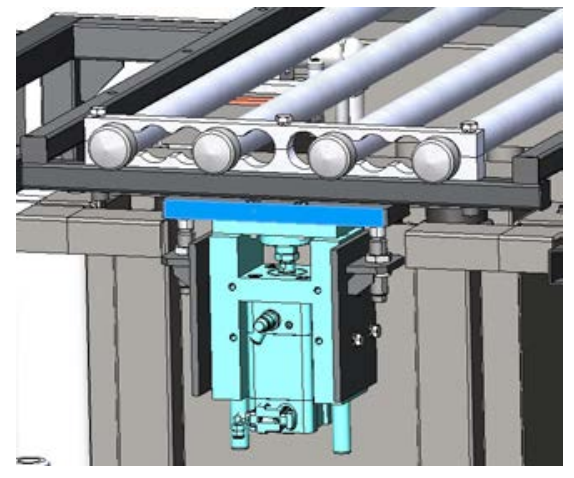

a)

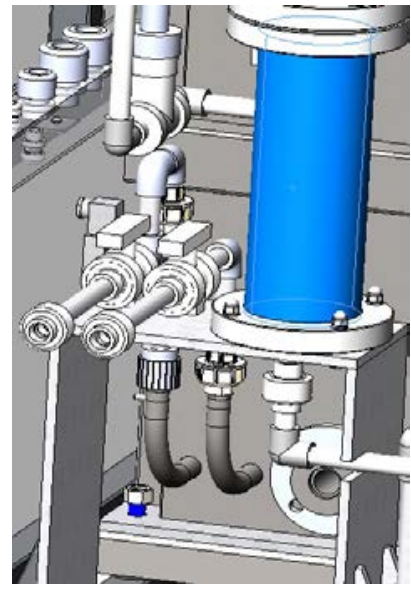

b)

Fig. 2. 3D-view of the unit's nodes

a)- pneumatic cylinder of the suspension shaking mechanism; $b$ )-fragment of the filtration unit

\section{Conclusion}

The paper presents the results of solving the problem of improving the design of the CNPU unit used for chemical nickel plating of parts made of corrosion-resistant and carbon steels, as well as aluminum, titanium, copper and their alloys with repeated use of the plating solution. The modernization of the unit was carried out taking into account the requirements listed above, which ensure the operation of the unit as a part of the plating 
line. The modernized chemical nickel-plating plant is more compact and easier to maintain, and its design makes it possible to operate as a part of a plating line. The overall dimensions of a single load of parts into the working area should not exceed $600 \times 400 \times 450$ (mm). Examples of such parts are gears, shafts, frames etc. The operation of the unit in a plating section of a real manufacturing facility showed its high efficiency.

\section{References}

1. P. R. Roberge, Handbook of corrosion engineering, Third Edit. New York: McGrawHill Education, 2019. 800 p.

2. K. Nemtinov, A. Eruslanov, and Y. Nemtinova, "Engineering design of a grain silo and a bucket elevator for a combined unit for hopper preparation and seeding of grain crops", E3S Web Conf., vol. 126, p. 00003, Oct. 2019. DOI : $10.1051 / \mathrm{e} 3$ sconf $/ 201912600003$

3. V. Nemtinov, N. Kryuchin, A. Kryuchin, and Y. Nemtinova, "Design and study of seeding devices for small selection seeding machines", E3S Web Conf., vol. 126, p. 00008, Oct. 2019. DOI: 10.1051/e3sconf/201912600008

4. V. Zaitsev, V. Konovalov, and Y. Rodionov, "Jamming of hand-operated riveter - the problem and solving it in process of modelling”, J. Phys. Conf. Ser., vol. 1278, p. 012015, Jul. 2019. DOI: 10.1088/1742-6596/1278/1/012015

5. A. Borisenko, M. Haidl, and S. Gorlatch, "A GPU parallelization of branch-andbound for multiproduct batch plants optimization”, J. Supercomput., vol. 73, no. 2, pp. 639-651, Feb. 2017. DOI: 10.1007/s11227-016-1784-x

6. L. J. Durney, Electroplating Engineering Handbook. Springer US, 2014. P.790

7. V. Nemtinov, V. Sergeev, and Y. Nemtinova, "Design development of technological complex for friction welding of thin-walled products made of armlen", IOP Conf. Ser. Mater. Sci. Eng., vol. 709, p. 033072, Jan. 2020. DOI: 10.1088/1757899X/709/3/033072

8. A. Ivannikov, V. Kulagin, A. Romanov, and B. Pozdneev, "Algebraic models of digital system design debugging decomposition”, in 2016 IEEE East-West Design \& Test Symposium (EWDTS), 2016, pp. 1-4. DOI: 10.1109/EWDTS.2016.7807712

9. V. Nemtinov, N. Bolshakov, and Y. Nemtinova, "Automation of the early stages of plating lines design", MATEC Web Conf., vol. 129, p. 01012, Nov. 2017. DOI: $10.1051 /$ matecconf $/ 201712901012$

10. O. Krol and V. Sokolov, "Development of models and research into tooling for machining centers", Eastern-European J. Enterp. Technol., vol. 3, no. 1 (93), pp. 1222, May 2018. DOI: 10.15587/1729-4061.2018.131778

11. V. Alekseev, D. Lakomov, A. Shishkin, G. Al Maamari, and M. Nasraoui, "Simulation images of external objects in a virtual simulator for training humanmachine systems operators", J. Phys. Conf. Ser., vol. 1278, p. 012032, Jul. 2019. DOI: 10.1088/1742-6596/1278/1/012032

12. L. W. McKeen, Fluorinated Coatings and Finishes Handbook, 2nd Editio. William Andrew, 2016. 630p. DOI: 10.1016/C2014-0-01971-5

13. F. Delaunois, V. Vitry, and L. Bonin, Electroless Nickel Plating: Fundamentals to Applications. Boka Raton: CRC Press, 2020. 446 p.

14. C. A. Loto, "Electroless Nickel Plating - A Review", Silicon, vol. 8, no. 2, pp. 177186, Apr. 2016. DOI: 10.1007/s12633-015-9367-7 
15. K. Mazur, A. Stefańska, and M. Hebda, "Analysis of Chemical Nickel-Plating Process", Mater. Sci., vol. 54, no. 3, pp. 387-394, Nov. 2018. DOI: 10.1007/s11003018-0196-x

16. V. Nemtinov, S. Terekhov, Y. Nemtinova, A. Borisenko, and S. Egorov, "Optimization model of heat supply consumers connection schedule to the heat supply system", in International Multidisciplinary Scientific GeoConference Surveying Geology and Mining Ecology Management, SGEM, 2017, vol. 17, no. 21, pp. 10131020. DOI: $10.5593 /$ sgem 2017/21/S07.128

17. A. Borisenko and S. Gorlatch, "Efficient GPU-parallelization of batch plants design using metaheuristics with parameter tuning", J. Parallel Distrib. Comput., vol. 154, pp. 74-81, Aug. 2021. DOI: 10.1016/j.jpdc.2021.03.012

18. A. Borisenko and S. Gorlatch, "Comparing GPU-parallelized metaheuristics to branch-and-bound for batch plants optimization", J. Supercomput., vol. 75, no. 12, pp. 7921-7933, Dec. 2019.DOI: 10.1007/s11227-018-2472-9

19. I. Sutton, Plant Design and Operations. Elsevier, 2015. 388p. DOI: 10.1016/C2013-0$14262-6$

20. V. Sokolov and O. Krol, "Installations Criterion of Deceleration Device in Volumetric Hydraulic Drive", Procedia Eng., vol. 206, pp. 936-943, 2017. DOI: 10.1016/j.proeng.2017.10.575

21. L. Kang and C. Yang, "A Review on High-Strength Titanium Alloys: Microstructure, Strengthening, and Properties", Adv. Eng. Mater., vol. 21, no. 8, p. 1801359, Aug. 2019. DOI: 10.1002/adem.201801359

22. M. Swapna Sai, V. Dhinakaran, K. P. Manoj Kumar, V. Rajkumar, B. Stalin, and T. Sathish, "A systematic review of effect of different welding process on mechanical properties of grade 5 titanium alloy," Mater. Today Proc., vol. 21, pp. 948-953, 2020. DOI: $10.1016 /$ j.matpr.2019.09.027

23. O. Krol and V. Sokolov, "Modelling of spindle nodes for machining centers", J.Phys. Conf. Ser., vol. 1084, p. 012007, Aug. 2018. DOI: 10.1088/1742-6596/1084/1/012007 